\title{
Verzeichnis der Abkürzungen, Formelzeichen und Indizes
}

\author{
Verzeichnis der Formelzeichen und Indizes \\ $>\quad$ größer als \\ $<\quad$ kleiner als \\ $\S \quad$ Paragraf \\ / pro \\ p probabilitas (Wahrscheinlichkeit) \\ $\% \quad$ Prozent
}

Verzeichnis der Abkürzungen

Abb. Abbildung

Abs. Absatz

Art. Artikel

APS adult protective services (Erwachsenenschutzdienst)

BAGSO Bundesarbeitsgemeinschaft für Senioren-Organisationen

BGB Bürgerliches Gesetzbuch

BMFSFJ Bundesministerium für Familie, Senioren, Frauen und Jugend

BMG Bundesministerium für Gesundheit

BVerfG Bundesverfassungsgericht

bzgl. bezüglich

bzw. beziehungsweise

ca. circa

CESCR International Covenant on Economic, Social and Cultural Rights (Internationaler Pakt über wirtschaftliche, soziale und kulturelle Rechte)

CEDAW Convention on the Elimination of All Forms of Discrimination Against Women (Übereinkommen zur Beseitigung jeder Form von Diskriminierung der Frau)

$\mathrm{cm} \quad$ Zentimeter

CRCT cluster-randomisierte kontrollierte Studie

d. h. das heißt

DIMR Deutsches Institut für Menschenrechte

EMRK Europäische Menschenrechtskonvention

et al. et alii, et aliae, et alia

etc. et cetera

FamFG Gesetz über das Verfahren in Familiensachen und in den Angelegenheiten der freiwilligen Gerichtsbarkeit

FEM freiheitsentziehende Maßnahme

ff. fortfolgend

ggfs. gegebenenfalls

GG Grundgesetz

ICD International Statistical Classification of Diseases and Related Health Problems

ICD.10 10. Revision der ICD

ICCPR International Covenant on Civil and Political Rights (Internationaler Pakt über bürgerliche und politische Rechte)

i.d.R. $\quad$ in der Regel 


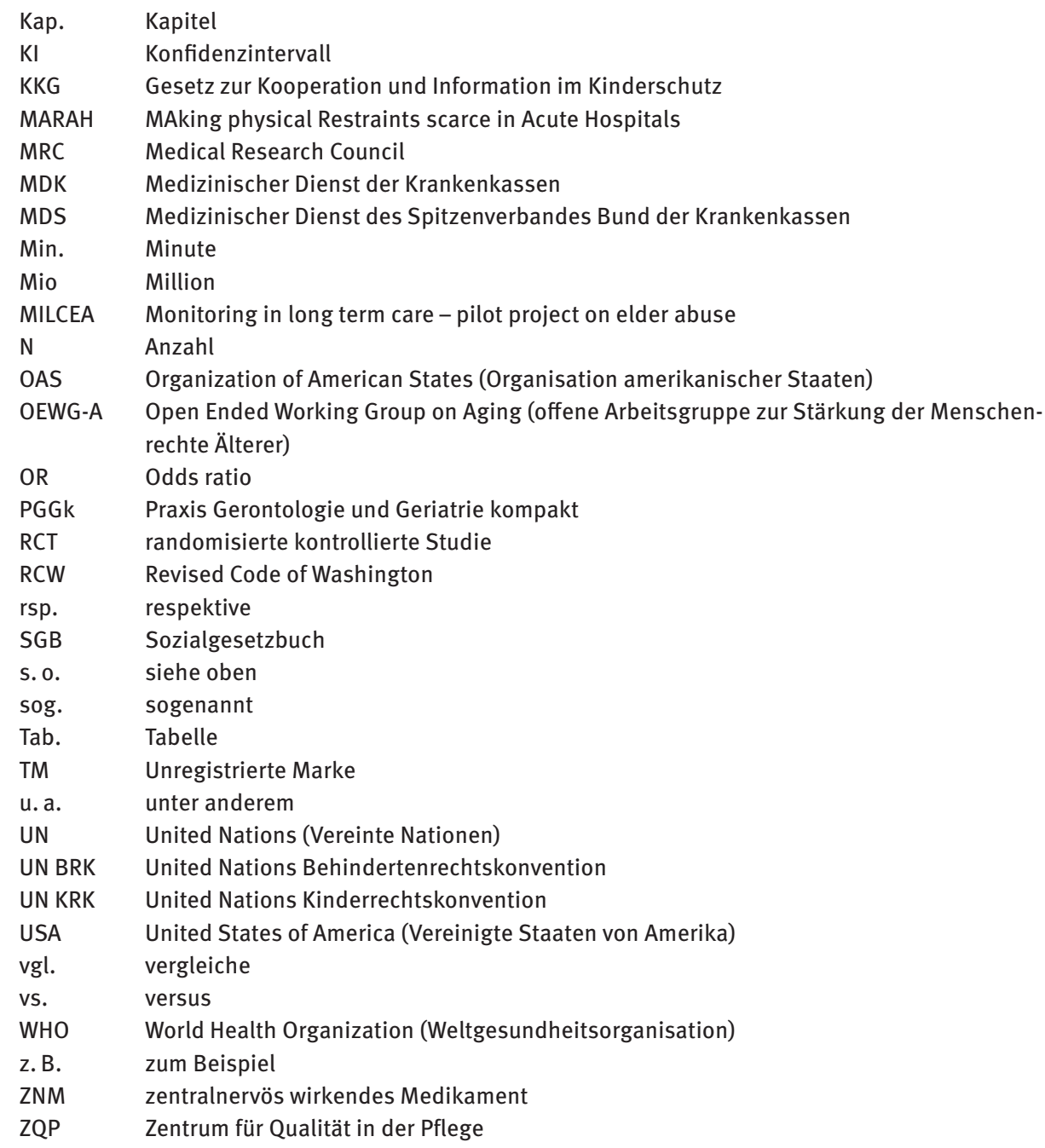

